\title{
Improvement of Titanium Corrosion Resistance by Coating with Poly-Caprolactone and Poly-Caprolactone/Titanium Dioxide: Potential Application in Heart Valves
}

\author{
Carolina Cruz Ferreira ${ }^{a}$, Virgilio Pereira Ricci ${ }^{a}$, Luciola Lucena de Sousa ${ }^{a}$, \\ Neide Aparecida Mariano ${ }^{a}$, Maria Gabriela Nogueira Campos ${ }^{a}$ \\ aInstituto de Ciência e Tecnologia, Universidade Federal de Alfenas, Rodovia José Aurélio Vilela, \\ 11.999, BR 267, Km 533, Cidade Universitária, 37.715-400, Poços de Caldas, MG, Brazil.
}

Received: April 29, 2017; Revised: October 28, 2017; Accepted: December 07, 2017

\begin{abstract}
Heart diseases affect part of world population and generally involves the functioning of valves. Valves replacement is the most common treatment and the choice between synthetic or natural/biological implants depends on several factors. Synthetic implants have greater durability, whereas biological ones are more biocompatible. This work proposes the use of polymeric coating on titanium metal surface to increase implant biocompatibility. Poly-caprolactone (PCL) has demonstrated greater efficacy for biomedical applications due to its biocompatibility. It can easily form films and coat surfaces. Titanium discs were submitted to alkaline and thermal treatments and coated with $1 \% \mathrm{PCL}$ and $1 \% \mathrm{PCL}+\mathrm{TiO}_{2}$. For both conditions, PCL crystals were found in titanium coated surface (SEM and EDX) and X-ray diffractogram confirmed PCL coating. Infrared Spectroscopy spectra showed both PCL and $\mathrm{TiO}_{2}$ characteristic peaks. Moreover, corrosion resistance of coated disc has considerably increased, proving the effectiveness of PCL as coating material and its potential application in cardiac valves.
\end{abstract}

Keywords: Poly-caprolactone, Titanium dioxide, Titanium, Coating, Heart Valves.

\section{Introduction}

Heart diseases affect a large part of the world population. In Brazil, they were the second cause of death. Certain heart diseases affect the functioning of the valves and different approaches are available for treatment ${ }^{1}$. The most common treatment for valve dysfunctions are based on surgical repair or replacement of the damaged valves ${ }^{2}$. The treatment choice depends on the analysis of the particularities of each patient, such as clinical, radiological and hemodynamic conditions, the evolutionary state of the disease and the dimensions of valves dysfunction ${ }^{1,2}$. For cases where the most indicated treatment is replacement, artificial prostheses (mechanical valves) or biological prostheses (human or animal valves) are employed. The key of mechanical valves are their durability $^{3}$.The main materials used in the manufacture of mechanical valves, such as those produced by BjorkShiley, LilleheiKaster, Omniscience, MedtronicHall or St.Judes, are pyrolytic carbon and titanium. These materials are more resistant, with greater durability without erosion or sharp wear, but still are susceptible to thrombogenic episodes, since these valves provide a surface on which blood clots can form easily ${ }^{1,4}$. Thus, a patient who has been implanted with a mechanical valve needs to be take anticoagulant medicine to prevent heart attack and stroke ${ }^{4}$. To eliminate this lifelong medication need after heart valve replacement, numerous studies have been developed in order to reduce the thrombogenicity of substitute valves $5,6,7,8$.
Polymers (natural and synthetic) have been shown to be potentially applicable to medical devices; however, mechanical properties of these materials might be a disadvantage for application in heart valves. An ideal heart valve substitute should be resistant, durable, hemocompatible, cost-effective and weightless ${ }^{3-8}$. Therefore, coating of metallic prosthesis with a polymeric material may be an interesting approach to overcome the biocompatibility issue of metals for heart valves applications. In addition, incorporation of inorganic materials in the polymeric coating may also improve mechanical properties of the composites ${ }^{9-12}$.

Titanium is considered the most biocompatible metal and is currently used on heart valves substitutes. Nevertheless, it is susceptible to corrosion by body fluids, which contain chloride ions and proteins. In the corrosion process, the metal is oxidized to its ionic form and the dissolved oxygen is reduced to hydroxide ions. Thus, byproducts of titanium corrosion may cause inflammatory responses in the body 9 Poly-caprolactone (PCL), an aliphatic polyester, is a synthetic polymer extensively used as biomaterial due to its biocompatibility, bioabsorption, low molecular weight/ density and low $\cos ^{8}{ }^{8,13}$. Titanium Oxide $\left(\mathrm{TiO}_{2}\right)$ is an inert and low cost inorganic material used as an additive in cosmetics and medicines because of its biocidal properties ${ }^{12}$. Incorporation of $\mathrm{TiO}_{2}$ in a PCL matrix for further coating of titanium surface would be a great alternative to increase the compatibility/adhesion of PCL/Titanium, since a $\mathrm{TiO}_{2}$ protective layer is naturally formed in the titanium surface. Therefore, the aim of this work is to study the effects of PCL 
and PCL incorporated with $\mathrm{TiO}_{2}$ coatings on the corrosion resistance of titanium for potential application as cardiac valves. Structural, morphological, chemical and electrostatic characterizations of the coated discs were performed by X-ray Diffractometry (XDR), Scanning Electron Microscopy (SEM), Energy Dispersive X-ray analysis (EDX), Infrared Spectroscopy (FTIR) and Corrosion test. Moreover, PCL and PCL incorporated with $\mathrm{TiO}_{2}$ films were analyzed by Differential Scanning Calorimetry (DSC).

\section{Materials and Methods}

\subsection{Materials}

Commercially pure titanium ( $\mathrm{Ti} \mathrm{cp}$ ) discs, grade $4,3 \mathrm{~mm}$ diameter and $5 \mathrm{~mm}$ thickness and chemical composition as shown in Table 1 (ASTM F67-06 ${ }^{14}$ ) was supplied. Polycaprolactone (Mn 70000-90000, density $1.145 \mathrm{~g} / \mathrm{mL}$ at $25^{\circ} \mathrm{C}$ ) was purchased from Sigma-Aldrich (USA). Titanium dioxide particles $\left(\mathrm{TiO}_{2}\right)$ was synthesized via microwave and ultrasound techniques.

Table 1. Chemical composition of Ti cp (\% w/w).

\begin{tabular}{cccccc}
\hline $\mathrm{Ti}$ & $\mathrm{Fe}$ & $\mathrm{O}$ & $\mathrm{C}$ & $\mathrm{N}$ & $\mathrm{H}$ \\
\hline \multirow{2}{*}{ Bal. } & 0.50 & 0.40 & 0.08 & 0.05 & 0.015 \\
& max. & max. & max. & max. & $\max$. \\
\hline
\end{tabular}

\subsection{Methods}

\subsubsection{Synthesis of $\mathrm{TiO}_{2}$}

The synthesis of $\mathrm{TiO}_{2}$ was performed in two steps: Microwave and Ultrasonic Synthesis. The mixture of titanium isopropoxide (98\%), citric acid and isopropanol $20 \%$ (v/v) was stirred until formation of the metal complex. Then, ethylene glycol was added to the mixture, which was subjected to microwave radiation in order to obtain a polymeric mass. The mass was calcined at $300^{\circ} \mathrm{C}$ for $2 \mathrm{~h}$. The obtained solid was macerated and calcined again at $700^{\circ} \mathrm{C}$ for $2 \mathrm{~h}$. The resulted powder was $\mathrm{TiO}_{2}$. Then, $0.4 \mathrm{~g}$ of $\mathrm{TiO}_{2}$ was dispersed in $8.6 \mathrm{M} \mathrm{NaOH}$ solution, sonicated for $2 \mathrm{~h}$ (Unique, USC 700) and centrifuged. Miliq water was used to wash the decanted solid, followed by the addition of $40 \mathrm{~mL}$ of methanol and dried on a heating plate.

\subsubsection{Alkaline and thermal treatments}

Ti cp discs were wet-grounded to $180 \mathrm{mesh}$ sandpaper, followed by an ultrasonic bath with detergent, distilled water and isopropyl alcohol. Subsequently, samples were immersed in a $5 \mathrm{M} \mathrm{NaOH}$ solution and placed in an oven at $60^{\circ} \mathrm{C}$ for 24 hours. The discs were submitted to thermal treatment at $600^{\circ} \mathrm{C}$ for 1 hour, and cooled to room temperature ${ }^{15}$.

\subsubsection{Characterization of treated/uncoated Ti $\mathrm{cp}$ discs}

\subsubsection{Microstructal analysis}

The microstructural characterization of alkali and thermally treated Ti cp discs was performed by Optical Microscopy (OM) and Scanning Electron Microscopy (SEM), according to ASTM E3-95 ${ }^{15}$. OM was performed using an optical microscope coupled to the Zeiss brand image analyzer, model AxioVision 4.8.2 SP1. SEM was performed in the FEI microscope, model Inspect 550, coupled to an EDA detector of the brand EDAX, model Apollo X. For SEM analysis, samples were fixed with a carbon tape. A Kroll solution ( $5 \%$ nitric acid, $10 \%$ hydrofluoric acid and $85 \%$ by volume distilled water) was used to reveal the microstructure.

\subsubsection{Hardness Testing}

The hardness measurements on the Ti cp discs were made in the Durometer, Pantec brand, model RASN RS and $\mathrm{RB}$ using a $120^{\circ}$ cone penetrator and a force of $150 \mathrm{Kgf}$.

\subsubsection{Preparation of coated Ti cp discs}

\subsubsection{Coating procedure}

Treated Ti cp discs were coated by PCL and PCL incorporated with $\mathrm{TiO}_{2}$. Firstly, the polymeric solution was prepared by dissolving PCL in chloroform in the ratio 1 : $100(\mathrm{w} / \mathrm{v})$. This solution was split in two flasks and $\mathrm{TiO}_{2}$ was added to one of them in the ratio 10:100 (w/w; $\mathrm{TiO}_{2} /$ PCL) under stirring. Ti cp discs were then immersed in the solutions for few seconds. After removal, the discs were dried at room temperature in a desiccator for 48 hours in order to obtain $\mathrm{Ti} \mathrm{cp}+\mathrm{PCL}$ and $\mathrm{Tic} \mathrm{p}+\mathrm{PCL}+\mathrm{TiO}_{2}$ samples. For characterization purposes, $\mathrm{PCL}$ and $\mathrm{PCL}+\mathrm{TiO}_{2}$ films were also prepared by solvent evaporation technique. The solutions were cast in a mold and dried at room temperature for 48 hours in order to obtain PCL and PCL+TiO ${ }_{2}$ samples.

\subsubsection{Infrared spectroscopy}

Infrared Spectroscopy analysis (FTIR) was performed on the Perkin Elmer Spectrometer Frontier FTIR using an Attenuated Total Reflection (ATR) accessory. No sample preparation was required. Ti cp disc (after alkaline and thermal treatment), PCL film, PCL $+\mathrm{TiO}_{2}$ film, Ti cp+PCL and Ti cp+PCL $+\mathrm{TiO}_{2}$ were analyzed from 500 to $4000 \mathrm{~cm}^{-1}$ in order to identify the characteristic functional groups present in each sample.

\subsubsection{X-ray Diffractiometry}

$\mathrm{X}$-ray diffraction analysis was performed in a Rigaku Diffractometer; model Ultima $\mathrm{IV}$, with $\mathrm{Cu} \mathrm{K} \alpha$ radiation. Ti cp disc, PCL film, PCL $+\mathrm{TiO}_{2}$ film, Ti cp+PCL and Ti $\mathrm{cp}+\mathrm{PCL}+\mathrm{TiO}_{2}$ were analyzed in a $2 \theta$ range from $10^{\circ}$ to 
$90^{\circ}$, with step of $0.02^{\circ}$ per $2 \mathrm{~s} /$ step in order to analyze the crystallinity of the samples.

\subsubsection{Thermal analysis}

The differential scanning calorimetry (DSC) analysis was performed on the Netzsch equipment, model DSC 200F3, to determine the melt temperature $\left(\mathrm{T}_{\mathrm{m}}\right)$ and fusion enthalpy $\left(\Delta \mathrm{H}_{\mathrm{m}}\right)$ of PCL and PCL $+\mathrm{TiO}_{2}$ films. Films were previously dried in a desiccator for 48 hours and cut into small pieces, totaling approximately $10 \mathrm{mg}$. Each sample was subjected to heating in an aluminum DSC sealed pan from $30^{\circ} \mathrm{C}$ up to $120^{\circ} \mathrm{C}$, at heating rate $10^{\circ} \mathrm{C} \mathrm{min}^{-1}$, under argon atmosphere. The degree of crystallinity of the PCL-based films was estimated by the following equation:

$$
\mathrm{Xc}(\%)=\Delta \mathrm{Hm} / \Delta \mathrm{H}^{0} \mathrm{~m} * 100 \%
$$

\section{Where:}

Xc: crystallinity degree

$\Delta \mathrm{Hm}$ : enthalpy of fusion of the film

$\Delta \mathrm{H}^{0} \mathrm{~m}$ : enthalpy of fusion of $100 \%$ crystalline PCL

\subsubsection{Scanning electron microscopy}

SEM micrographs of samples were obtained in a FEI microscope, model Inspect 550, coupled to an EDA detector of the brand EDAX, model Apollo X. Films were previously dried in a desiccator for 48 hours and superficial morphology of the samples was analyzed.

\subsubsection{Corrosion testing}

The open-circuit polarization corrosion (OCP) and potentiodynamic polarization tests were performed using an electrochemical cell, working electrode, platinum counter electrode and the saturated calomel electrode (SCE) and an electrolytic solution (1.5 $\mathrm{PBS} \mathrm{pH}=7.4$ at $36.5^{\circ} \mathrm{C}$ ). Potentiostatic and Potentialdynamic Anodic Polarization measurement were taken in by varying the corrosion potential (E) from $-1.5 \mathrm{~V}$ (ECS) to $+3.0 \mathrm{~V}$ with a $0.001 \mathrm{~V}$ pitch and a $0.001 \mathrm{~V} /$ second sweep speed, in order to obtain polarization curves for each sample.

\section{Results and Discussion}

Titanium discs were submitted to alkaline and thermal treatments in order to clean the surface and improve coatings adhesion $^{16,17}$. Chemical changes and changes of Ti oxidation states may be resulted from these treatments ${ }^{17}$. Moreover, microstructural characterization should be performed in order to evaluate the consequences of the treatments on the phase analysis.

\subsection{Characterization of treated/uncoated Ti cp discs}

\subsubsection{Microscopic analysis}

Commercially pure titanium (Ti cp) micrographs obtained by OM and SEM are shown in Figure 1. It is possible to observe a homogeneous distribution with axial granular structure. The presence of twins, which is a type of crystalline surface defect, where a small displacement of the atoms from their regular positions occurs, is characteristic of the alpha phase of titanium ${ }^{18}$.

\subsubsection{Hardness testing}

Ti cp hardness $34.4 \pm 1.5$ were measured by the Rockwell hardness (HRC). This result is in accordance to the Literature (33.2) $)^{18}$. Hardness is an important property for biomedical application of titanium, since it has to endure tensile forces, compression or shear and does not demonstrate a fragile behavior ${ }^{16,17}$. Moreover, durability is one of the most important parameter for heart valve application because it involves continuously operation. Tobaruela et al. (2016) investigated the variation of indentation-hardness with the fatigue-life in bioprosthetic heart valves. The authors reported a significant correlation of hardness with fatigue performance, suggesting that hardness may be a reliable indicator of mechanical performance and durability ${ }^{19}$.

\subsection{Preparation of coated Ti cp discs}

Coating of titanium discs with PCL and PCL incorporated with $\mathrm{TiO}_{2}$ was successful and no bubbles were observed. PCL formed a transparent film in the surface of the disc, while $\mathrm{PCL}+\mathrm{TiO}_{2}$ formed a white film. Both films homogeneously coated the titanium surface and remained adhered to it during all characterization procedures. (a)

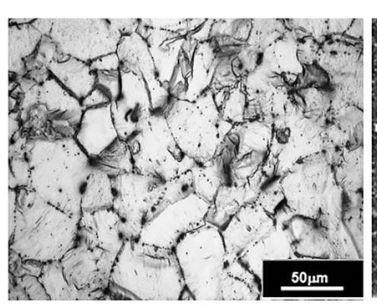

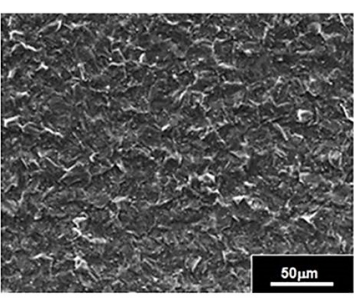

(b)
Figure 1. Micrograph of Ti cp after alkaline and thermal treatments and reaction with Kroll solution. (a) Micrograph obtained by Optical Microscopy; (b) Micrograph obtained by Scanning Electron Microscopy. 


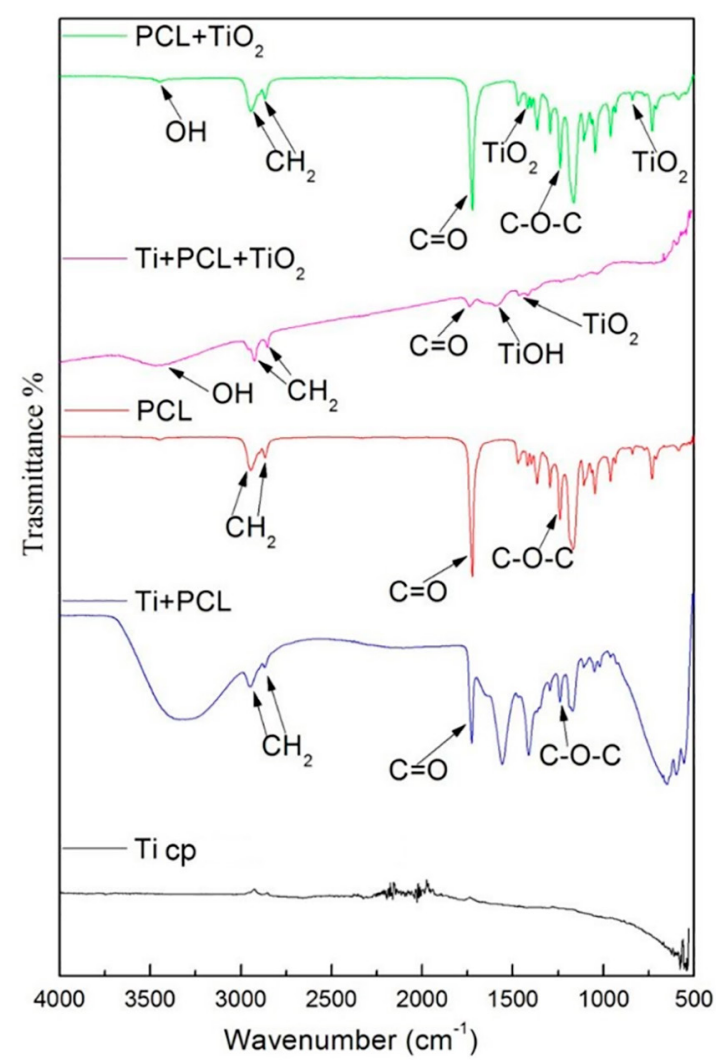

Figure 2. Infrared spectra of (black) Ti cp, (blue) Ti cp+PCL, (red) PCL film, (pink) Ticp+PCL+TiO2, and (green) $\mathrm{PCL}+\mathrm{TiO}_{2}$ film.

\subsection{Infrared analysis}

The presence of $\mathrm{PCL}$ and $\mathrm{TiO}_{2}$ in the coated discs was evaluated by FTIR analysis. The spectra of $\mathrm{PCL}$ and $\mathrm{PCL}+\mathrm{TiO}_{2}$ films, Ti cp, Ti cp+PCL, Ti cp+PCL $+\mathrm{TiO}_{2}$ are shown in Figure 2. The bands located at 762 and $1265 \mathrm{~cm}^{-1}$ are related to the vibration absorption of $\mathrm{TiO}_{2}$. The broad band in the region between $3670-3570 \mathrm{~cm}^{-1}$ refers to the stretching of the $\mathrm{OH}$ group. Among the characteristic vibrations of the PCL, the absorption bands 1233, 1107 and $1042 \mathrm{~cm}^{-1}$ correspond to the asymmetric COC vibration. The band at $1726 \mathrm{~cm}^{-1}$ is attributed to the stretching vibration of the carbonyl groups $(\mathrm{C}=\mathrm{O})$ present in the PCL. The absorption bands in the range of 2862 and $2942 \mathrm{~cm}^{-1}$ are due to the deformation of $\mathrm{CH}_{2}$ of the PCL interconnected to the inorganic network. The band observed at $1576 \mathrm{~cm}^{-1}$ is attributed to vibrations of hydroxyl group bound to the surficial Ti present in the oxide. The oxygen atom present in the $\mathrm{OH}$ group may be coordinated with several neighboring metal atoms. Thus, the superficial hydroxyl may occur in the free form (Ti-OH) linked by hydrogen to each other or linked to chemically adsorbed water molecules in the surface of $\mathrm{TiO}_{2}$. Therefore, interfacial forces between the PCL matrix and the titanium oxide network is mainly established by hydrogen bonds ${ }^{20}$. Catauro et al. (2015) also investigated PCL-TiO interactions by FTIR analysis ${ }^{20}$. The authors were able to confirm these

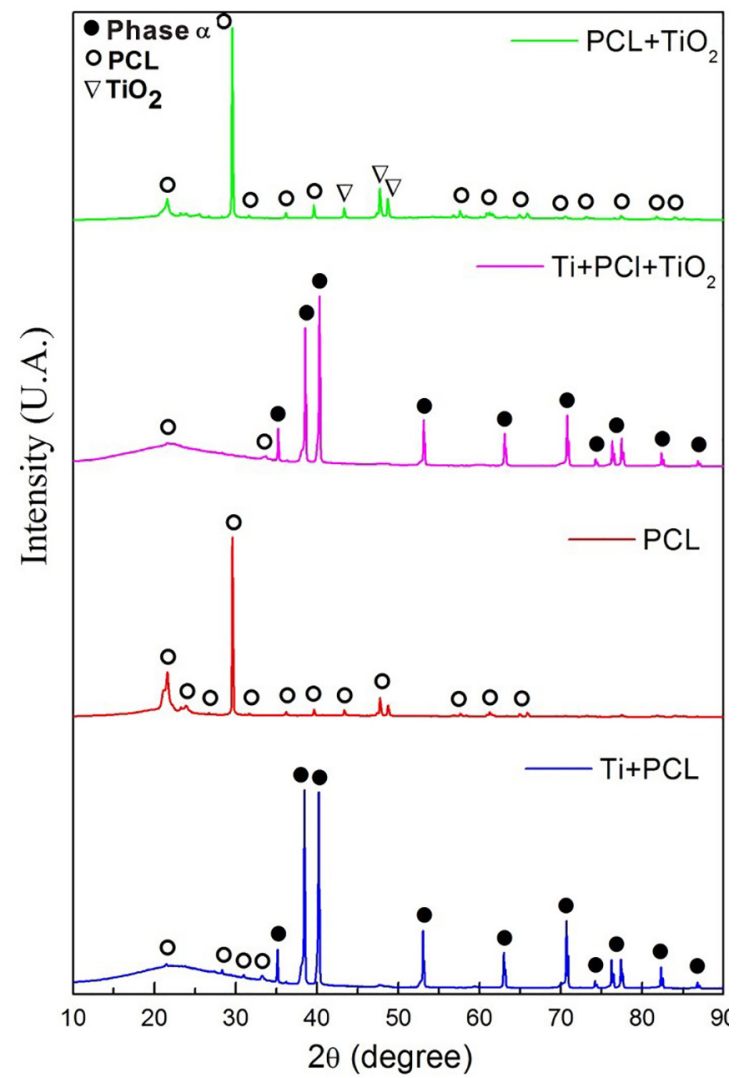

Figure 3. X-ray Diffractograms of (blue) Ti cp+PCL, (red) PCL film, (pink) $\mathrm{Ti} \mathrm{cp}+\mathrm{PCL}+\mathrm{TiO}_{2}$, and (green) $\mathrm{PCL}+\mathrm{TiO}_{2}$ film.

interactions by the changes on the relative intensity of the bands related to the ester groups found in polymer chain ${ }^{20}$. According to them, the symmetrical and asymmetrical stretching of the $\mathrm{C}-\mathrm{O}-\mathrm{C}$ bonds and the $\mathrm{O}-\mathrm{C}$ vibrations can be use as characteristic peaks of $\mathrm{PCL}^{20}$.

\subsection{XRD analysis}

$\mathrm{XRD}$ analysis also confirmed the coating efficiency of $\mathrm{PCL} / \mathrm{PCL}+\mathrm{TiO}_{2}$. Figure 3 shows the diffractograms of Ti cp, PCL and PCL $+\mathrm{TiO}_{2}$ films, and the coated discs Ti $\mathrm{cp}+\mathrm{PCL}$, $\mathrm{Ti} \mathrm{cp}+\mathrm{PCL}+\mathrm{TiO}_{2}$. The characteristic peaks of the titanium $\alpha$-phase can be found in the diffractograms of Ti cp, Ti cp+PCL, Ti cp+PCL+TiO ${ }_{2}$. This $\alpha$-phase has a compact hexagonal structure. In addition, the diffractograms of $\mathrm{PCL}, \mathrm{PCL}+\mathrm{TiO}_{2}, \mathrm{Ti} \mathrm{cp}+\mathrm{PCL}$ and $\mathrm{Ti}$ $\mathrm{cp}+\mathrm{PCL}+\mathrm{TiO}_{2}$ indicate the presence of characteristic peaks of PCL. PCL presents an X-ray pattern with two intense reflection peaks at $2 \theta=21^{\circ}$ and $29^{\circ}$ that can be easily identified in all diffractograms ${ }^{21}$. Characteristic peaks of $\mathrm{TiO}_{2}$ depend on the crystallographic phase. XRD patterns of rutile phase exhibited strong diffraction peaks at $27^{\circ}$, $36^{\circ}$ and $55^{\circ}$, while anatase phase patterns exhibited strong diffraction peaks at $25^{\circ}$ and $48^{\circ 22}$. Therefore, some of $\mathrm{TiO}_{2}$ diffraction peaks overlap PCL ones. According to Figure 
3 , $\mathrm{TiO}_{2}$ characteristic peaks were not identified in the $\mathrm{Ti}$ $\mathrm{cp}+\mathrm{PCL}+\mathrm{TiO}_{2}$ diffractogram. This can be attributed to the low concentration of $\mathrm{TiO}_{2}$ dispersed in the PCL matrix as well as to the overlap peaks. Nevertheless, the presence of $\mathrm{TiO}_{2}$ in the $\mathrm{Ti} \mathrm{cp}+\mathrm{PCL}+\mathrm{TiO}_{2}$ diffractogram can be confirmed by the reduced the intensity of the characteristic peak of PCL at $2 \theta=21^{\circ}$. This reduction can be due to the interactions between PCL and $\mathrm{TiO}_{2}$.

Shoja et al. (2006) reported that PCL characteristic peaks were no longer observed in the XRD of $\mathrm{PCL} / \mathrm{TiO}_{2}$ microcomposites with of $15 \% \mathrm{TiO}_{2}(\mathrm{w} / \mathrm{w})$, indicating that the inorganic networks act by confining PCL crystallization in the films ${ }^{11}$.

\subsection{Thermal analysis}

The interactions between PCL and $\mathrm{TiO}_{2}$ were also evaluated by DSC. Figure 4 shows the DSC curves obtained for PCL and $\mathrm{PCL}+\mathrm{TiO}_{2}$ films. According to the curves, the melting temperatures are $62.6^{\circ} \mathrm{C}$ and $61.8^{\circ} \mathrm{C}$ for PCL and $\mathrm{PCL}+\mathrm{TiO}_{2}$ films, respectively. Therefore, the presence of $\mathrm{TiO}_{2}$ did not significantly influence the melting temperature of the composite film. Similar behavior was reported by Wei et al. $(2011)^{21}$. The authors investigated the crystallization behavior of $\mathrm{PCL} / \mathrm{TiO}_{2}$ nanocomposites obtained by in situ polymerization and suggested that the addition of $\mathrm{TiO}_{2}$ into PCL matrix does not affect the melting temperature in the thermodynamic equilibrium ${ }^{21}$.

The experimental fusion enthalpy was obtained from the area below the peak in the DSC curve. Contrary to melting temperature, the enthalpy of fusion of $\mathrm{PCL}+\mathrm{TiO}_{2}$ film $(63.69 \mathrm{~J} / \mathrm{g})$ was significantly reduced compared to those found for the PCL film (76.27J/g). By equation 1 and using the enthalpy of fusion of $100 \%$ crystalline PCL as $135 \mathrm{~J} / \mathrm{g}$, it was possible to estimate the degree of crystallinity of the films ${ }^{23}$. PCL film showed higher degree of crystallinity (56.5\%) than $\mathrm{PCL}+\mathrm{TiO}_{2}$ film $(47.2 \%)$, indicating that $\mathrm{TiO}_{2}$ limited PCL crystallization in the films, as well as observed by XDR analysis. Wei et al. (2011) reported that $\mathrm{TiO}_{2}$ had a great heterogeneous nucleation effect on the crystallization

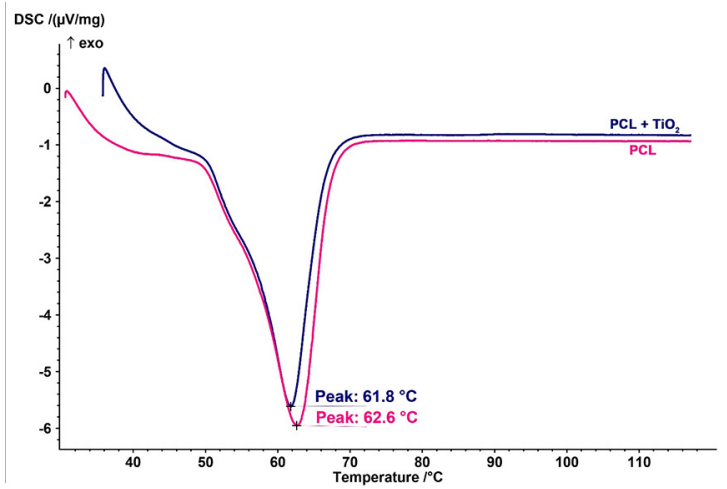

Figure 4. Differential Scanning Calorimetry curves of (pink) PCL film and (blue) $\mathrm{PCL}+\mathrm{TiO}_{2}$ film. of PCL matrix ${ }^{21}$. They suggest that $\mathrm{TiO}_{2}$ nanoparticles added to the PCL matrix play two competing roles on PCL crystallization: particles act as heterogeneous nuclei and promote the crystallization process of PCL; and they physically prevent polymer chain mobility and retard PCL crystals growth $^{21}$. Thus, the reduced crystallinity degree obtained for the $\mathrm{PCL}+\mathrm{TiO}_{2}$ film may be due to the higher contribution of $\mathrm{TiO}_{2}$ in reducing PCL mobility and the crystals growth rate.

Chin-San (2004) investigated the in situ polymerization of titanium isopropoxide in poly-caprolactone ${ }^{24}$. According to this author, $\mathrm{TiO}_{2}$ influences the strength of interfacial bonding between the polymer chains and affects crystallization of $\mathrm{PCL}^{24}$.

\subsection{Scanning electron microscopy}

The morphology of PCL crystals was evaluated by SEM. SEM micrographs of PCL and PCL+TiO 2 films are shown in Figures 5a and 5b, respectively. Spherulites can be observed in Figure 5a. On the other hand, a large number, but smaller, PCL spherulitus was found in $\mathrm{PCL}+\mathrm{TiO}_{2}$ film micrograph (Figure 5b). Thus, the nucleating effect of $\mathrm{TiO}_{2}$ on PCL crystallization can be confirmed by the increase of crystals amount and the reduction on the spherulites diameter. Similar EDS spectra was found for PCL and $\mathrm{PCL}+\mathrm{TiO}_{2}$ films, identifying the main chemical elements found in PCL (carbon and oxygen). Titanium was not present in the $\mathrm{PCL}+\mathrm{TiO}_{2}$ film spectrum due to the lower concentration of this element in the film composition. The EDS spectra of Ti cp+PCL and Ti cp $+\mathrm{PCL}+\mathrm{TiO}_{2}$ (Figures $5 \mathrm{c}$ and $5 \mathrm{~d}$ ) indicate the presence of $\mathrm{C}$ and $\mathrm{O}$ species in both discs, as characteristics elements of PCL. The presence of $\mathrm{Na}$ peaks in these spectra is due to $\mathrm{NaOH}$ used in the alkaline treatment of the discs. The darkest background region observed in Figures $4 \mathrm{c}$ and $4 \mathrm{~d}$ corresponds to the $\mathrm{Ti}$ matrix. In both micrographs, PCL is uniformly coating all the extension of the discs. Moreover, PCL crystals clusters can be found along the discs.

\subsection{Corrosion testing}

In order to evaluate the efficiency of PCL and PCL $+\mathrm{TiO}_{2}$ coatings on Ti cp discs, corrosion test was performed at physiological conditions ( $\mathrm{pH} 7.4$ and $36.5^{\circ} \mathrm{C}$ ). Corrosion of implants can alter the $\mathrm{pH}$ locally, and the release of metallic ions may affect surround cells metabolism.

The electrochemical parameters of the corrosion test (Ecorr - corrosion potential, Icorr - corrosion current and Ipass - passivation current) for PCL and PCL $+\mathrm{TiO}_{2}$ films, Ti cp, Ti cp+PCL, Ti cp+PCL+TiO, samples are shown in Table 2. In addition, Figure 6 shows the potentiodynamic polarization curves for all tested samples. Ti cp presents a clear region of passivation, with the formation of the passive layer $\left(\mathrm{I}_{\text {pass }}=1.97 \times 10^{-5} \mathrm{~A} / \mathrm{cm}^{2}\right)$, which breaks at a potential around $1.5 \mathrm{~V}^{25}$. However, this behavior does not occur to 


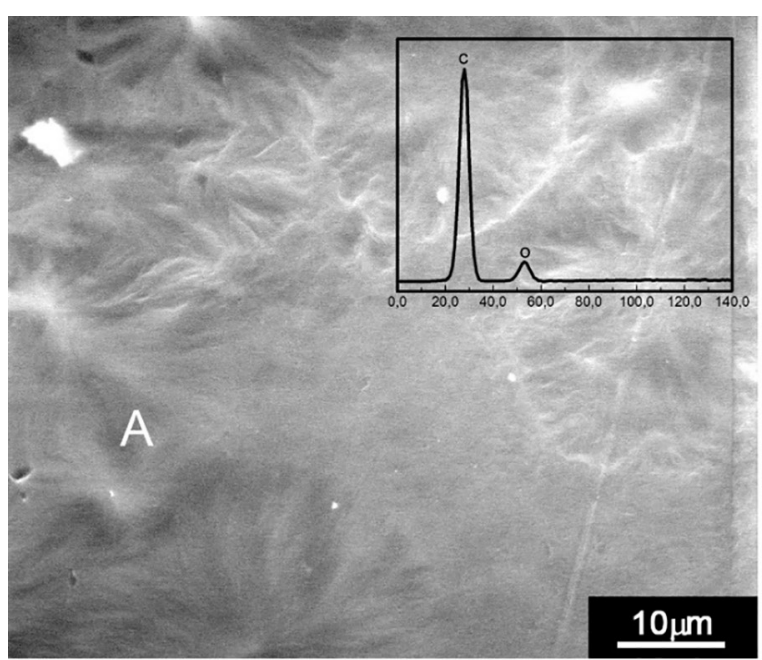

(a)

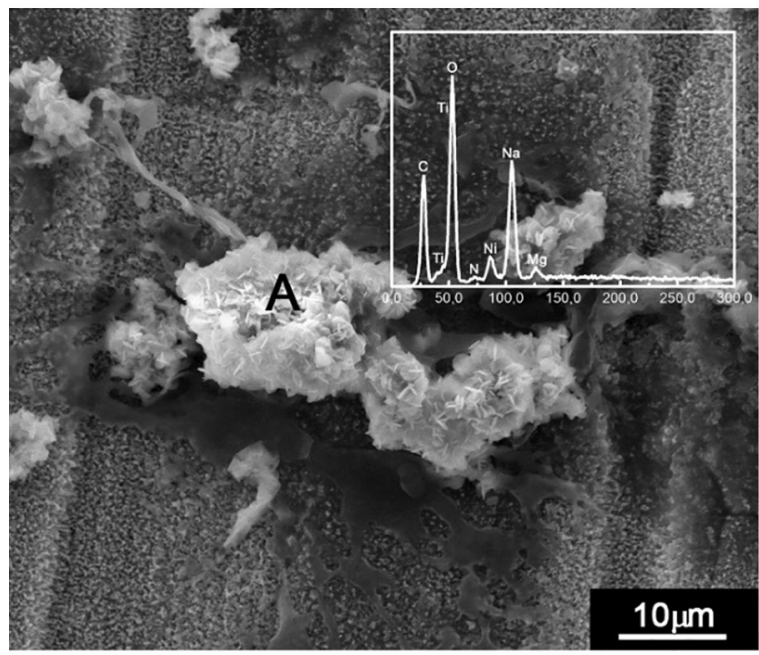

(c)

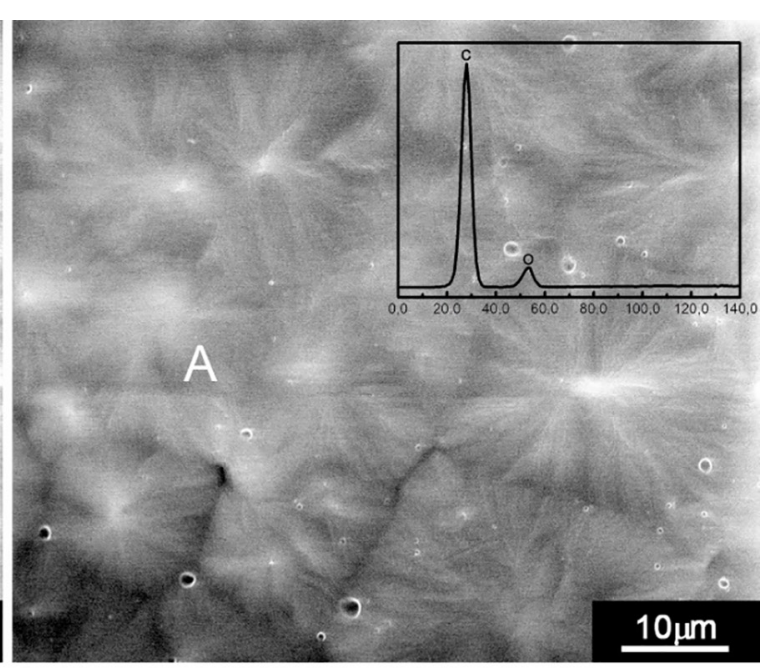

(b)

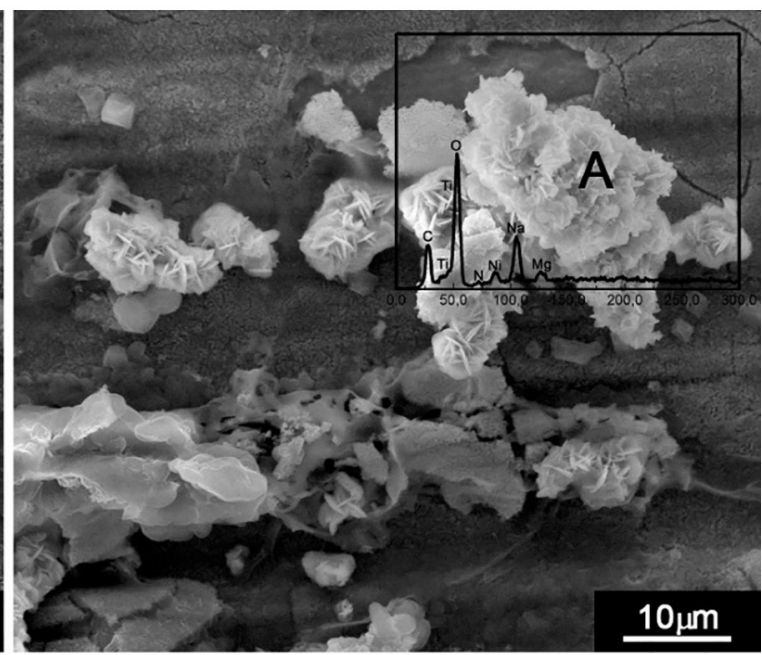

(d)

Figure 5. Micrographs obtained by Scanning Electron Microscopy and EDS spectra obtained at the point A: (a) PCL film, (b) $\mathrm{PCL}+\mathrm{TiO}{ }_{2}$ film, (c) $\mathrm{Ti} \mathrm{cp}+\mathrm{PCL}$, and (d) $\mathrm{Ti} \mathrm{cp}+\mathrm{PCL}+\mathrm{TiO}_{2}$.

Table 2. Corrosion Test results at physiological conditions.

\begin{tabular}{cccc}
\hline Samples & $\mathrm{E}_{\text {corr }}(\mathrm{V})$ & $\mathrm{I}_{\text {corr }}\left(\mathrm{A} / \mathrm{cm}^{2}\right)$ & $\mathrm{I}_{\text {pass }}\left(\mathrm{A} / \mathrm{cm}^{2}\right)$ \\
\hline $\mathrm{Ti} \mathrm{cp}$ & -0.4863 & $7.18 \times 10^{-6}$ & $1.97 \times 10^{-5}$ \\
$\mathrm{Ti} \mathrm{cp}+\mathrm{PCL}$ & -0.3061 & $6.63 \times 10^{-6}$ & $1.07 \times 10^{-4}$ \\
$\mathrm{Ti} \mathrm{cp}+\mathrm{PCL}+\mathrm{TiO}_{2}$ & -0.3250 & $2.53 \times 10^{-6}$ & $1.05 \times 10^{-4}$ \\
$\mathrm{PCL}$ & -0.5825 & $7.36 \times 10^{-5}$ & $7.65 \times 10^{-4}$ \\
$\mathrm{PCL}+\mathrm{TiO}_{2}$ & -0.2732 & $2.42 \times 10^{-5}$ & $5.67 \times 10^{-3}$ \\
\hline
\end{tabular}

$\mathrm{E}_{\text {corr }}$ : corrosion potential; $\mathrm{I}_{\text {corr }}$ : corrosion current density; $\mathrm{I}_{\text {pass }}$ : passivation current density.

the coated samples $\mathrm{Ti} \mathrm{cp}+\mathrm{PCL}$ and $\mathrm{Ti} \mathrm{cp}+\mathrm{PCL}+\mathrm{TiO}_{2}$ (no rupture of the film was observed during the test).

As it can be seen in the polarization curves, both coated samples ( $\mathrm{Ti} \mathrm{cp}+\mathrm{PCL}$ and $\mathrm{Ti} \mathrm{cp}+\mathrm{PCL}+\mathrm{TiO}_{2}$ ) presented similar behavior. Thus, the presence of $\mathrm{TiO}_{2}$ did not alter corrosion resistance. The passivation current density in these coated samples were similar across a wide range of potential, indicating the formation of a compact passive film (possibly titanium oxide) on the surface of Ti cp. Moreover, the higher passivation current density of the 


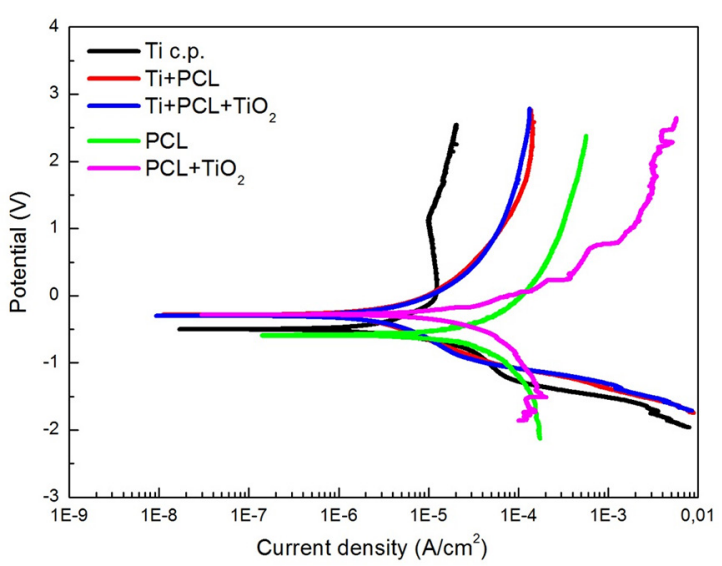

Figure 6. Polarization curves obtained at physiological condition: (black) $\mathrm{Ti} \mathrm{cp}$, (red) $\mathrm{Ti} \mathrm{cp}+\mathrm{PCL}$, (blue) $\mathrm{Ti} \mathrm{cp}+\mathrm{PCL}+\mathrm{TiO}_{2}$, (green) PCL film, and (pink) PCL $+\mathrm{TiO}_{2}$ film.

coated samples indicates that the passivation happens first in the $\mathrm{Ti} \mathrm{cp}+\mathrm{PCL}$ and $\mathrm{Ti} \mathrm{cp}+\mathrm{PCL}+\mathrm{TiO}_{2}$ than in the Ti cp, protecting the metal from corrosion ${ }^{25,26}$.

Corrosion potential $\left(\mathrm{E}_{\text {corr }}\right)$ of Ti cp $+\mathrm{PCL}$ and $\mathrm{Ti} \mathrm{cp}+\mathrm{PCL}+\mathrm{TiO}_{2}$ are similar, but higher than $\mathrm{Ti} \mathrm{cp}$ one. This indicates that coated discs are more stable and that the coatings slow the onset of the corrosive process ${ }^{25}$. For heart valves application, corrosion stability at physiological condition plays an important role on the implant durability. Therefore, the use of PCL and $\mathrm{PCL}+\mathrm{TiO}_{2}$ may protect the implant against body fluids attack and improve its biocompatibility ${ }^{27}$. Nevertheless, biological tests of coating materials are necessary to subsidize biocompatibility aspects ${ }^{28}$.

\section{Conclusions}

We successfully coated titanium discs with poly-caprolactone and poly-caprolactone incorporated with titanium dioxide. The coated discs were more resistant to corrosion at physiological conditions. Therefore, poly-caprolactone and poly-caprolactone incorporated with titanium dioxide are potential surface-coating of titanium for heart valve applications.

\section{Acknowledgements}

The authors thank Brazilian research funding agencies FAPEMIG, CNPq and CAPES for financial.

\section{References}

1. Edmunds L. Evolution of prosthetic heart valves. American Heart Journal. 2001;141(5):849-855.

2. Mansur Filho J. Trombose de prótese valvular e tratamento trombolítico. Revista SOCERJ. 2001;XIV(1):88-94.

3. Ghanbari H, Viatge H, Kidane A, Burriesci G, Tavakoli M, Seifalian A. Polymeric heart valves: new materials, emerging hopes. Trends in Biotechnology. 2009;27(6):359-367.
4. Gracioli EC, Winter P, Ziulkoski AL, Spilki F, Dullius J, Einloft $\mathrm{S}$, et al. Dispositivos poliméricos cardiovasculares: comportamento termomecânico e viabilidade celular. Matéria (Rio de Janeiro). 2013;18(2):1313-1322.

5. Venkatraman S, Boey F, Lao LL. Implanted cardiovascular polymers: Natural, synthetic and bio-inspired. Progress in Polymer Science. 2008;33(9):853-874.

6. Schoen FJ. Cardiovascular pathology: maturation of a discipline and the Society for Cardiovascular Pathology. Cardiovascular Pathology. 2010;19(4):198-200.

7. Liu X, Chu PK, Ding C. Surface modification of titanium, titanium alloys, and related materials for biomedical applications. Materials Science and Engineering: R: Reports. 2004;47(34):49-121.

8. Catauro M, Bollino F, Papale F. Surface modifications of titanium implants by coating with bioactive and biocompatible poly ( $\varepsilon$-caprolactone) $/ \mathrm{SiO}_{2}$ hybrids synthesized via sol-gel. Arabian Journal of Chemistry. 2015. In Press.

9. Catauro M, Bollino F, Papale F, Giovanardi R, Veronesi P. Corrosion behavior and mechanical properties of bioactive sol-gel coatings on titanium implants. Materials Science and Engineering: C. 2014;43:375-382.

10. Catauro M, Bollino F, Veronesi P, Lamanna G. Influence of PCL on mechanical properties and bioactivity of $\mathrm{ZrO}_{2}$-based hybrid coatings synthesized by sol-gel dip coating technique. Materials Science and Engineering: C. 2014;39:344-351.

11. Shoja M, Shameli K, Ahmad MB, Zakaria Z. Preparation and characterization of Poly ( $\varepsilon$ - Caprolactone) $/ \mathrm{TiO}_{2}$ microcomposites. Digest Journal of Nanomaterials and Biostructures. 2015;10(2):471-477.

12. Muñoz-Bonilla A, Cerrada ML, Fernández-García M, Kubacka A, Ferrer M, Fernández-García M. Biodegradable PolycaprolactoneTitania Nanocomposites: Preparation, Characterization and Antimicrobial Properties. International Journal of Molecular Sciences. 2013;14(5):9249-9266.

13. Smith CM, Roy TD, Bhalkikar A, Li B, Hickman JJ, Church $\mathrm{KH}$. Engineering a titanium and polycaprolactone construct for a biocompatible interface between the body and artificial limb. Tissue Engineering Part A. 2010;16(2):717-724.

14. ASTM International. ASTM F67-06 - Standard Specification for Unalloyed Titanium, for Surgical Implant Applications (UNS R50250, UNS R50400, UNS R50550, UNS R50700). West Conshohocken: ASTM International; 2006.

15. ASTM International. ASTM E3-95 - Standard Practice for Preparation of Metallographic Specimens. West Conshohocken: ASTM International; 2001.

16. Jokanović V, Vilotijević M, Jokanović B, Jenko M, Anžel I, Stamenković D, et al. Investigations of corrosion on the surface of titanium substrate caused by combined alkaline and heat treatment. Corrosion Science. 2014;82:180-190.

17. Majumdar P, Singh SB, Chakraborty M. The role of heat treatment on microstructure and mechanical properties of Ti-13Zr-13Nb alloy for biomedical load bearing applications. Journal of the Mechanical Behavior of Biomedical Materials. 2011;4(7):1132-1144. 
18. Gammon LM, Briggs RD, Packard JM, Batson KW, Boyer R, Domby CW. Metallography and Microstructures of Titanium and Its Alloys. ASM Handbook. 2004;9:899-917.

19. Tobaruela A, Rojo FJ, García Paez JM, Bourges JY, Herrero EJ, Millán I, et al. Indentation hardness: A simple test that correlates with the dissipated-energy predictor for fatigue-life in bovine pericardium membranes for bioprosthetic heart valves. Journal of the Mechanical Behavior of Biomedical Materials. 2016;61:55-61.

20. Catauro M, Papale F, Bollino F. Characterization and biological properties of $\mathrm{TiO}_{2} / \mathrm{PCL}$ hybrid layers prepared via sol-gel dip coating for surface modification of titanium implants. Journal of Non-Crystalline Solids. 2015;415:9-15.

21. Wei Z, Wang G, Wang P, Liu L, Qi M. Crystallization behavior of poly( $\varepsilon$-caprolactone) $/ \mathrm{TiO}_{2}$ nanocomposites obtained by in situ polymerization. Polymer Engineering \& Science. 2012;52(5):1047-1057.

22. Thamaphat K, Limsuwan P, Ngotawornchai B. Phase Characterization of TiO2 Powder by XRD and TEM. Kasetsart Journal (Natural Science). 2008;42:357-361.
23. Borghesi DC, Molina MF, Guerra MA, Campos MGN. Biodegradation Study of a Novel Poly-Caprolactone-Coffee Husk Composite Film. Materials Research. 2016;19(4):752-758.

24. Wu CS. In situ polymerization of titanium isopropoxide in polycaprolactone: Properties and characterization of the hybrid nanocomposites. Journal of Applied Polymer Science. 2004;92(3):1749-1757.

25. Mariano NA, Oliveira RG, Fernandes MA, Rigo ECS. Corrosion behavior of pure titanium in artificial saliva solution. Matéria (Rio de Janeiro). 2009;14(2):878-880.

26. Mariano NA, Oliveira RG, Braga EI, Rigo ECS. Corrosion Characterization of Titanium Alloys by Electrochemical Techniques in Artificial Saliva and SBF Solution. Key Engineering Materials. 2009;396-398:315-318.

27. Lam MT, Wu JC. Biomaterial applications in cardiovascular tissue repair and regeneration. Expert Review of Cardiovascular Therapy. 2012;10(8):1039-1049.

28. De Viteri VS, Fuentes E. Titanium and Titanium Alloys as Biomaterials. In: Gegner J, ed. Tribology - Fundamentals and Advancements. Rijeka: InTech; 2013. Available from: https:// www.intechopen.com/books/tribology-fundamentals-andadvancements/titanium-and-titanium-alloys-as-biomaterials. Access in: 19/12/2017. 